\title{
The MTHFR 677T Allele May Influence the Severity and Biochemical Risk Factors of Alzheimer's Disease in an Egyptian Population
}

\author{
Nasser Attia Elhawary, ${ }^{1,2}$ Doaa Hewedi, ${ }^{3}$ Arwa Arab, ${ }^{4}$ Salwa Teama, ${ }^{5}$ Hassan Shaibah, \\ Mohammed Taher Tayeb, ${ }^{1}$ and Neda Bogari ${ }^{1}$ \\ ${ }^{1}$ Department of Medical Genetics, Faculty of Medicine, Umm Al-Qura University, P.O. Box 57543, Makkah 21955, Saudi Arabia \\ ${ }^{2}$ Department of Molecular Genetics, Medical Genetics Center, Faculty of Medicine, Ain Shams University, Cairo 11566, Egypt \\ ${ }^{3}$ Department of Psychiatry, Faculty of Medicine, Ain Shams University, Cairo 11566, Egypt \\ ${ }^{4}$ Department of Psychology, Faculty of Arts and Humanities, King Abdulaziz University, P.O. Box 80200, Jeddah 21589, Saudi Arabia \\ ${ }^{5}$ Department of Clinical Pathology, Medical Research Center, Faculty of Medicine, Ain Shams University, P.O. Box 80200, \\ Cairo 11566, Egypt \\ ${ }^{6}$ Department of Anatomy, Faculty of Medicine, Umm Al-Qura University, P.O. Box 7607, Makkah 21955, Saudi Arabia
}

Correspondence should be addressed to Nasser Attia Elhawary; nasgenet@hotmail.com

Received 15 July 2013; Revised 18 September 2013; Accepted 20 September 2013

Academic Editor: Fabrizia Bamonti

Copyright (C) 2013 Nasser Attia Elhawary et al. This is an open access article distributed under the Creative Commons Attribution License, which permits unrestricted use, distribution, and reproduction in any medium, provided the original work is properly cited.

\begin{abstract}
Objective. We evaluated whether the methylenetetrahydrofolate reductase (MTHFR) 677C $>\mathrm{T}$ marker influences the risk and severity of Alzheimer's disease (AD) and whether $\mathrm{AD}$ is associated with homocysteine, vitamin B12, and cholesterol levels in Egypt. Methods. Forty-three Alzheimer's cases and 32 non-AD controls were genotyped for the 677C>T polymorphism. Clinical characteristics and levels of homocysteine, vitamin B12, and cholesterol were assessed. Results. No significant differences in the frequencies of the MTHFR alleles or genotypes between $\mathrm{AD}$ cases and controls $(P=0.14)$ were identified. The $677 \mathrm{~T}$ mutant allele was significantly overrepresented in $\mathrm{AD}$ cases compared to controls $(\mathrm{OR}=2.22 ; P=0.03)$. The $677 \mathrm{~T} / \mathrm{T}$ frequency was three times higher in $\mathrm{AD}$ patients than in controls, which could increase plasma homocysteine levels. Severe cases of AD were the most frequent in patients with the T/T genotype (11.6\%). The effect of the MTHFR polymorphism on the risk of AD may be independent of homocysteine, vitamin B12, or even cholesterol levels. Conclusions. The MTHFR 677C>T polymorphism-especially the presence of one copy of the $\mathrm{T}$ allele-appears to confer a potential risk for the development of AD. The T/T genotype may contribute to hypercysteinemia as a sensitive marker.
\end{abstract}

\section{Introduction}

Alzheimer's disease (AD, MIM 104300) is a major cause of disability in the elderly population. It is the most common form of dementia, affecting 1 in 8 individuals older than 60 years of age [1]. Most AD cases are late in onset and are probably influenced by both genetic and environmental factors. Clinically, AD generally begins with subtle shortterm memory problems and then progresses to difficulties in memory, language, and orientation. In the late stage of $\mathrm{AD}$, ventricular enlargement and shrinkage of the brain may be observed by magnetic resonance imaging. Some characteristic changes in the AD brain include neuronal loss in selected regions; intracellular neurofibrillary tangles in the neurons of the cerebral cortex and hippocampus; and neuritic plaques containing amyloids that may be further surrounded by dystrophic neurites, reactive astrocytes, and microglia [1].

Alzheimer Disease International estimates that there are currently 30 million cases of dementia in the world, with 4.6 million new cases occurring annually [2]. Statistics is much more ambiguous in the developing world, where few studies have examined the prevalence of dementia and where estimates vary widely. Evidence on the prevalence of $\mathrm{AD}$ is abundant in Europe and North America, patchy in South and 
Southeast Asia, and very limited in Africa, the Middle East, Russia, Eastern Europe, and Latin America [3].

Historically, the ancient Egyptians had words for the skull, brain, vertebrae, spinal fluid, and meninges and had described unconsciousness, quadriparesis, hemiparesis, and dementia [4]. Egypt has been the interest of many conquerors since the times of the ancient Pharaohs until the Arab-Israeli conflict, including the Osmania Empire, the French campaign, and British domination. Consequently, much intermarriage has occurred in Egypt, which could be reinforcing the heterogeneity, pleiotropy, and variable expressivity of hereditary disorders [5]. AD, in Egypt, has been reported as the most common form of dementia, accounting for $51.2 \%$ of all hereditary cases. Vascular dementia accounts for $28.7 \%$ of hereditary cases, general medical conditions such as Parkinsonism or Lewy body dementia for $12.8 \%$, and multiple etiologies for 7.3\% [4]. El Tallawy et al. [6] have reported that the prevalence of dementia in Egypt is $2.26 \%$ among those $\geq 50$ years, $4.45 \%$ among those $\geq 60$ years, $9.28 \%$ among those $\geq 70$ years, and $18.48 \%$ among those $\geq 80$ years. The Middle East is expected to face an increasing burden of $\mathrm{AD}$ as the population naturally ages.

Although a polymorphism in the apolipoprotein $\mathrm{E}$ $(A p o E)$ gene has been found to be associated with familial $\mathrm{AD}$, it might not provide a sensitivity or high-enough specificity to be used alone as a diagnostic test for the disease [7].

Much attention has been focused on the association between the rs1801133 single nucleotide polymorphism (SNP) in the methylenetetrahydrofolate reductase (MTHFR, MIM 607093) gene and AD. Genetic variations in this candidate gene may increase homocysteine levels or decrease levels of vitamin B12 $[8,9]$. The MTHFR enzyme regulates homocysteine concentrations in humans and has been implicated in the pathogenesis of cardiovascular disease [10], congenital abnormalities [11], cancer [12], and psychiatric disorders [13].

Several MTHFR polymorphisms can cause severe homocystinuria or moderate or mild hyperhomocysteinemia. The most frequent rs1801133 SNP (Ala>Val) in the MTHFR gene renders the MTHFR enzyme thermolabile and is linked to moderate hyperhomocysteinaemia [14]. Hyperhomocysteinaemia elevates the risk of mild cognitive impairment and dementia of the Alzheimer's type [15]. However, some studies have reported that an increase in plasma homocysteine may be an independent risk factor for the development of $\mathrm{AD}$ [16].

B12 deficiency $(<150 \mathrm{pmol} / \mathrm{L})$ is associated with AD. Even the subclinical low normal range of B12 levels $(<250 \mathrm{pmol} / \mathrm{L})$ is associated with $\mathrm{AD}$, vascular dementia, and Parkinson's disease [9]. An association between $\mathrm{AD}$ and a low concentration of serum vitamin $\mathrm{B} 12$ has been described [9]. Additional data suggest that high intake of vitamin B12 is related to a low risk of $\mathrm{AD}$. It has been reported that $\mathrm{B}$ vitamins may efficiently decrease the plasma level of the amyloid $\mathrm{A} \beta 40$ and thus have a role in preventing $\mathrm{AD}$ [17]. However, no association has been found between vitamin B12 intake and the risk of developing $\mathrm{AD}[18]$.

Cholesterol is another factor that may have direct implications for AD. It has been shown that animals fed a diet supplemented with $2 \%$ cholesterol have increased $A \beta$ in the brain cortex and hippocampus. Furthermore, impaired brain cholesterol dynamics have been described as a potential cause of AD [19].

Despite the weight of genetic information on AD, only a few reports provide evidence on genetic-biochemical interactions that affect the risk of AD. Most of these reports are from Western countries. Our hypothesis is that the frequency of the $\mathrm{T}$ allele and of the T/T genotype of the rs1801133 SNP will be highly compared to the $\mathrm{C}$ allele and the $\mathrm{C} / \mathrm{C}$ genotype or will be increasingly associated with the severe form of $\mathrm{AD}$ among Egyptians.

The aim of this study was to determine the genotype and allele frequencies of the rs1801133 SNP and to evaluate the influence of genotype on risk and severity of disease in Egyptian patients with AD. The study also sought to determine any associations between $\mathrm{AD}$ and either clinical characteristics or homocysteine, vitamin B12, and cholesterol levels in these patients.

\section{Subjects and Methods}

2.1. Population. The study was conducted among 75 elderly Egyptians (43 patients with $\mathrm{AD}$ plus 32 nondemented controls). All patients over the age of 59 years who were in the database at the Memory Disorder and Old Age Psychiatry Clinic, Psychiatry Department, Ain Shams University, Cairo, Egypt, over a six-month period were considered for inclusion in the study.

The National Institute of Neurological and Communicative Disorders and Stroke-Alzheimer's Disease and Related Disorders Association (NINCDS-ADRDA) criteria were used to diagnose possible and probable AD. ICD-10 was among the clinical diagnostic criteria employed in this study. Mean cognitive test scores for $\mathrm{AD}$ patients were $12.3 \pm 6.6$ on the mini-mental state examination (MMSE), $31.8 \pm 10.9$ on the activities of daily living (ADL) index, and $12.1 \pm 7.3$ on the blessed dementia scale (BDS). Patients were examined for the presence of some of the vascular diseases common in Egyptians, such as diabetes mellitus type 2 and hypertension, and for the effects of anti-inflammatory drugs. The severity of $\mathrm{AD}$ was categorized as mild, moderate, or severe based on the stages of the clinical dementia rating (CDR).

$\mathrm{AD}$ cases were considered familial if dementia was documented in at least two first-degree relatives within two generations. If a reliable family history was not available, cases were termed sporadic. Cases were defined as early onset if age of onset was $<65$ years with $\mathrm{AD}$ and as late onset if age of onset was $>65$ years. Suspected cases of AD or other types of dementia were further examined by senior physicians through laboratory tests, clinical features, and neuropsychological tests.

Of 55 patients with $\mathrm{AD}, 43$ cases ( 29 women and 14 men) were analyzed. Twelve patients (21.8\%) refused to be clinically investigated or could not be located for followup. Twelve (27.9\%) of the 43 patients had early-onset $\mathrm{AD}$, and 31 (72.1\%) had late-onset $\mathrm{AD}$. The ages of the patients were 60-64 years (27.9\%), 65-69 years (27.9\%), $70-79$ years $(23.2 \%)$, and $\geq 80$ years $(21.0 \%)$. 
We also examined a sample of 32 age-matched nondemented Egyptians (22 women and 10 men) who were recruited as controls from the local community where they were living unassisted. All controls were carefully assessed using a rigorous clinical history and CT scans and standard neuropsychological examinations to exclude any neurological disorders. Each member of the control group had an MMSE score $\geq 24$, indicating that they were cognitively normal. The ages of the non-demented controls were 60-64 years (28.1\%), $65-69$ years (28.1\%), $70-79$ years $(25 \%)$, and $\geq 80$ years $(18.8 \%)$.

This study was approved by the local Bioethics Committee. Patients or their caregivers provided written informed consent.

2.2. DNA Isolation. Genomic DNA was extracted from peripheral blood $(0.2 \mathrm{~mL})$ using the QIAamp DNA Blood kit (Qiagen Gm6H, Hilden, Germany). In some cases, DNA was prepared in situ by gently scraping the buccal mucosa for $30 \mathrm{~s}$ using a cytobrush [33]. The cells obtained were treated directly with diluted $\mathrm{NaOH}$ solution, heated, and neutralized with Tris-Cl, pH 8.0. A $2.5 \mu \mathrm{L}$ volume of buccal cells typically sufficed for amplification by polymerase chain reaction (PCR).

2.3. Genotyping of the rs1801133 Locus. Previously reported primers for the rs1801133 SNP-the forward primer $5^{\prime}$-TGA AGG AGA AGG TGT CTG CGG GA-3' and the reverse primer $5^{\prime}$-AGG ACG GTG CGT GAG AGT G-3' [14]-were used to amplify the 198-bp target region within the MTHFR gene. We performed 35 rounds of polymerase chain reaction (PCR) on thermal cycler Engine Dyad (Bio-Rad Laboratories Inc., USA) with annealing at $58^{\circ} \mathrm{C}$ for $30 \mathrm{~s}$ followed by final extension of $7 \mathrm{~min}$. The PCR product was incubated with two units of the HinfI enzyme at $37^{\circ} \mathrm{C}$ for $16 \mathrm{~h}$ (Fermentas $\mathrm{GmbH}$, Germany). The digestion product was separated on a 3\% MetaPhor agarose gel (BMA, Rockland, ME, USA). The product was then identified by ethidium bromide staining and was photographed using a gel-documentation system (GBox, SynGene, Frederick, MD, USA). Positive controls for wild and variant genotypes were compared with the study samples (Figure 1). A positive control was used for each polymorphism. The genotypes of all samples were reassessed twice to confirm the results and ensure reproducibility. Some suspected genotypes were validated by purifying the PCR products using automated Agencourt AMPure XP kit (Beckman Coulter, Canada) and genotyping using Genetic Analyzer 3500 (ABI, Life Technologies, USA).

2.4. Biochemical Methods. Fasting homocysteine and vitamin B12 levels were assessed in all $\mathrm{AD}$ cases and controls. Homocysteine levels in blood plasma were measured with a fluorescence polarization assay (Abbott IMX Homocysteine Assay), and plasma vitamin B12 levels were measured by immunoassay. Reference ranges were $4-12 \mu \mathrm{mol} / \mathrm{L}$ for homocysteine and $157-1059 \mathrm{pg} / \mathrm{mL}$ for vitamin B12. Total lipids were measured using Roche Cobas Integra 400 PlusChemistry Analyzer (Diamond Diagnostics, MA, USA).

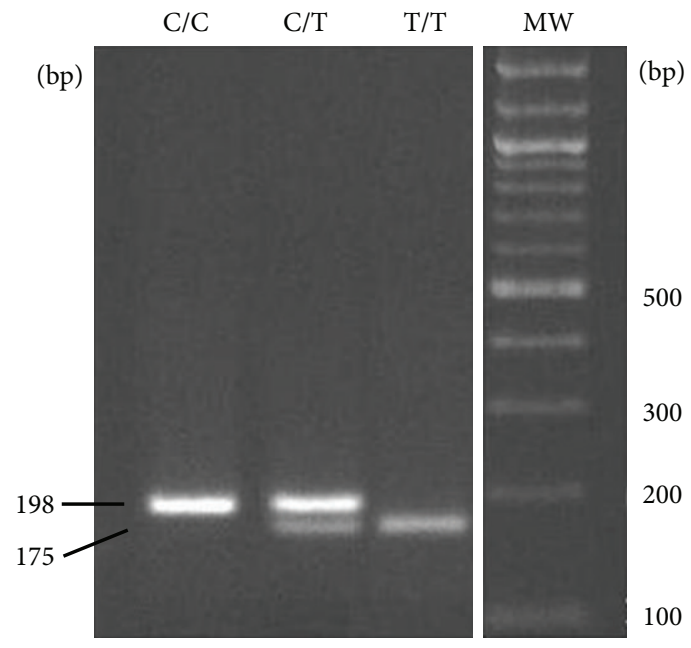

FIGURE 1: Electrophoretic gel pattern of the $677 \mathrm{C}>\mathrm{T}$ polymorphism in the MTHFR gene. The C allele gives the uncut 198-bp PCR product. The $\mathrm{T}$ allele, having a HinfI restriction site, appears as a 175-bp product. The 23-bp fragment of the $\mathrm{T}$ allele is not shown on the gel. The $\mathrm{C} / \mathrm{T}$ genotype is heterozygous.

2.5. Data Analysis. Possible associations between genotypes and the clinical severity of disease were analyzed using the Mantel-Haenszel $\chi^{2}$ test for linear association (SPSS ver. 20.0, SPSS Inc., Chicago, IL USA). The distribution of the control genotypes was checked for the Hardy-Weinberg equilibrium using the $\chi^{2}$ test (http://www.oege.org/software/hwe-mr-calc .shtml).

The Student's $t$-test, $\chi^{2}$ test, and $F$-test were used to compare continuous and categorical variables. Multivariate logistic regression analysis was performed to assess the contributions of MTHFR $677 \mathrm{C}>\mathrm{T}$ alleles and other independent risk factors to the study outcomes. A probability $<0.05$ was considered statistically significant. The odds ratio (OR) and relative risk of the $677 \mathrm{~T}$ allele at a $95 \%$ confidence interval (CI) were also calculated using MedCalc for Windows, version 12.3.0.0 (MedCalc software, Mariakerke, Belgium).

We used $G^{*}$ Power software (Germany, version 3.1.5, http://www.psycho.uni-duesseldorf.de/abteilungen/aap/gpower3/download-and-register/) to perform priori power analysis to estimate sufficient sample sizes to achieve adequate power for $\mathrm{z}$-testing of two independent proportions. Priori sample size estimations were performed using known information on the common allele frequencies in $\mathrm{AD}$ and demented healthy controls, a criterion probability of $\alpha=0.05$, and a power sensitivity of $80 \%$.

\section{Results}

The genotype distribution and allele frequencies of the rs1801133 SNP are shown in Table 1. The genotype frequencies satisfied the Hardy-Weinberg equilibrium in the controls, and the difference between the expected and observed values for the control genotypes was not significant $\left(\chi^{2}=0.24 ; P=\right.$ $0.63)$. 
TABLE 1: Genotype distribution and allele frequencies for the MTHFR rs1801133 single nucleotide polymorphism in Alzheimer's cases and controls.

\begin{tabular}{|c|c|c|c|c|c|c|c|c|}
\hline \multirow{2}{*}{ Group } & \multirow{2}{*}{ No. of patients } & \multicolumn{3}{|c|}{ Genotype $n(\%)$} & \multirow{2}{*}{$\chi^{2}$} & \multirow{2}{*}{$P$ value } & \multicolumn{2}{|c|}{ Allele frequency $n(\%)$} \\
\hline & & $\mathrm{C} / \mathrm{C}$ & $\mathrm{C} / \mathrm{T}$ & $\mathrm{T} / \mathrm{T}$ & & & $\mathrm{C}$ & $\mathrm{T}$ \\
\hline EAD & 12 & $7(58.3)$ & $3(25.0)$ & $2(16.7)$ & 2.00 & $0.37^{\mathrm{a}}$ & $17(0.71)$ & $7(0.29)$ \\
\hline LOAD & 31 & $11(35.5)$ & $14(45.2)$ & $6(19.4)$ & 1.02 & $0.28^{\mathrm{b}}$ & $36(0.58)$ & $26(0.42)$ \\
\hline AD cases & 43 & $7(58.3)$ & $17(39.5)$ & 8 (18.6) & 3.99 & $0.14^{\mathrm{c}}$ & $53(0.62)$ & $33(0.38)^{d}$ \\
\hline Controls & 32 & $20(62.5)$ & $10(31.2)$ & $2(6.3)$ & & & $50(0.78)$ & $14(0.22)$ \\
\hline
\end{tabular}

Abbreviations. AD: Alzheimer's disease, EAD: early-onset AD, LOAD: late-onset AD.

${ }^{a}$ No significant difference in genotype distributions between EAD and LOAD cases $(P>0.05)$.

${ }^{\mathrm{b}}$ No significant difference in allele frequencies between EAD and LOAD cases $(P>0.05)$.

${ }^{\mathrm{c}}$ No significant difference in genotypes between $\mathrm{AD}$ cases and controls $(P>0.05)$.

${ }^{\mathrm{d}}$ Significant difference in the frequencies of the T alleles between $\mathrm{AD}$ cases and controls ( $\mathrm{OR}=2.22(95 \% \mathrm{CI}, 1.1-4.6 ; P=0.03)$ ).

The $677 \mathrm{C} / \mathrm{C}$ genotype was more frequent in controls (62.5\%) than in $\mathrm{AD}$ cases (41.9\%). Although there were no significant differences in the frequencies of the MTHFR alleles or genotypes between $\mathrm{AD}$ cases and controls $\left(\chi^{2}=\right.$ 3.99; $P=0.14$ ), the frequency of the $677 \mathrm{~T} / \mathrm{T}$ genotype was three times higher for AD cases than for controls $(18.6 \%$ versus $6.3 \%$ ). Also, the frequency of the heterozygous $\mathrm{C} / \mathrm{T}$ genotype was higher for $\mathrm{AD}$ cases (40\%) than for controls (31\%) (Table 1). There was no significance difference between early-onset $\mathrm{AD}(n=12)$ and late-onset $\mathrm{AD}(n=31)$ regarding genotype distributions or allele frequencies $(P=$ 0.37 or $P=0.28$, resp.) (Table 1 ).

As for allele frequency, the $\mathrm{T}$ allele was significantly overrepresented in the $\mathrm{AD}$ group when compared with the control group (38\% versus $22 \%$ ). The C allele was more frequent than the $\mathrm{T}$ allele in both $\mathrm{AD}$ cases and controls ( $62 \%$ versus $38 \%$ and $78 \%$ versus $22 \%$, resp.) (Table 1 ). The OR of the mutant $\mathrm{T}$ allele outcome was 2.22 (95\% CI, 1.1-4.6; $Z=2.13 ; P=0.03)$. Consequently, the relative risk of the mutant $\mathrm{T}$ allele outcome was 1.75 (95\% CI, 1.0-3.0; $Z=2.06$; $P=0.04)$.

As shown in Table 2, the $677 \mathrm{C}>\mathrm{T}$ polymorphism was nearly significantly associated with the severity of $\mathrm{AD}\left(\chi^{2}=\right.$ 7.2; $P=0.05)$. Of the $43 \mathrm{AD}$ cases, $26(60.5 \%)$ were mild, $6(14.0 \%)$ were moderate, and $11(25.6 \%)$ were severe. Severe $\mathrm{AD}$ was more frequent in patients with the $677 \mathrm{~T} / \mathrm{T}$ genotype (11.6\%) than in patients with the $\mathrm{C} / \mathrm{C}(9.4 \%)$ or $\mathrm{C} / \mathrm{T}(4.7 \%)$ genotypes.

In terms of clinical characteristics (Table 3), the majority of $\mathrm{AD}$ cases were sporadic (95.3\%) with a late age of onset (58\%). Of the 43 patients with $\mathrm{AD}, 19 \%$ were illiterate, $72 \%$ had $<8$ years of education, and $9 \%$ had a higher level of education. About $40 \%$ of the women and $40 \%$ of the men were factory workers, and $18 \%$ of the women and $32 \%$ of the men were farmers. There were no significant effects of diabetes type 2, hypertension, anti-inflammatory drugs, or other psychiatric disorders on the incidence of $\mathrm{AD}(P>$ 0.05).

As shown in Table 3, the mean level of total homocysteine in plasma was significantly higher in $\mathrm{AD}$ cases $(18.4 \pm$ $6.3 \mu \mathrm{mol} / \mathrm{L})$ than in controls $(13.0 \pm 3.8 \mu \mathrm{mol} / \mathrm{L})(P<$ 0.0001 ). Moreover, plasma homocysteine was significantly higher in $\mathrm{AD}$ cases with the T/T genotype $(P<0.05)$ than
TABLE 2: Genotype distribution of the rs1801133 single nucleotide polymorphism and severity of Alzheimer's disease.

\begin{tabular}{lcccc}
\hline $\begin{array}{l}\text { Severity of Alzheimer's } \\
\text { disease }^{\mathrm{a}}\end{array}$ & $\begin{array}{c}\text { Patients } \\
n(\%)\end{array}$ & \multicolumn{4}{c}{ Cenotype $n(\%)$} \\
\hline Mild & $26(60.5)$ & $3(7.0)$ & $14(32.6)$ & $9(20.9)$ \\
Moderate & $6(14.0)$ & $1(2.3)$ & $1(2.3)$ & $4(9.3)$ \\
Severe & $11(25.6)$ & $4(9.4)$ & $2(4.7)$ & $5(11.6)$ \\
\hline
\end{tabular}

${ }^{a}$ The severity of Alzheimer's disease was evaluated using stages of the clinical dementia rating (CDR). In this rating, a null value is used for no dementia; 0.5 for questionable dementia; and 1, 2, and 3 for mild, moderate, and severe dementia, respectively.

in those with the $\mathrm{C} / \mathrm{T}$ or $\mathrm{C} / \mathrm{C}$ genotype. The mean level of vitamin $\mathrm{B} 12$ was significantly lower in $\mathrm{AD}$ patients $(310.1 \pm$ $120.2 \mathrm{pg} / \mathrm{mL})$ than in controls $(400.2 \pm 238.0 \mathrm{pg} / \mathrm{mL})(P=$ 0.0005). According to results of the lipid assessment, the mean level of total cholesterol in the AD group was slightly higher than the reference range, but this difference was not significant $(P>0.05)$ (Table 3$)$.

\section{Discussion}

Although environmental factors clearly influence the onset, progression, and severity of $\mathrm{AD}$, family studies indicate that genetic variation also influences susceptibility. As shown in Table 4, the frequencies of the T allele and of the homozygous mutant genotype 677T/T in our Egyptian population (38.4\% and $18.6 \%$, resp.) are midway between the frequencies in Caucasians, who have the lowest frequencies [20], and East Asians, who have the highest frequencies [30].

Whether the $677 \mathrm{C}>\mathrm{T}$ polymorphism is a risk factor for $\mathrm{AD}$ has been addressed in several populations, as shown in Table 4 . However, only a few studies have reported a positive association [21, 23, 32]. There are cross-population differences in the frequency of the $677 \mathrm{~T} / \mathrm{T}$ genotype in patients with $\mathrm{AD}$, ranging from $8 \%$ in Caucasian-Polish populations to $44 \%$ in East Asian (Chinese) [30]. In addition, the 677T allele frequency ranges from $27-30 \%$ in Polish populations [20] to $62 \%$ in Korean populations [32].

A meta-analysis has recently shown that the MTHFR $677 \mathrm{C}>\mathrm{T}$ polymorphism can cause AD susceptibility in East 
TABLE 3: Clinical characteristics and plasma levels of homocysteine, vitamin B12, and lipids in Alzheimer's cases and controls.

\begin{tabular}{|c|c|c|c|}
\hline Parameter & AD cases & Controls & Reference values \\
\hline Number of patients & 43 & 32 & \\
\hline Gender ratio (male: female) & $1: 2.1$ & $1: 2.2$ & \\
\hline Age range, years & $60-88$ & $60-88$ & \\
\hline Mean age $\pm S D$, years & $69.2 \pm 8.1$ & $70.7 \pm 8.8 y$ & \\
\hline Late onset $(>65 y)^{\mathrm{a}}$ & $25(58.1 \%)$ & - & \\
\hline Family history, $(+)^{\mathrm{a}, \mathrm{b}}$ & $2(4.7 \%)$ & $0(0 \%)$ & \\
\hline Educational level $(<8 \mathrm{y})^{\mathrm{a}}$ & $39(91 \%)$ & $26(81 \%)$ & \\
\hline Diabetes Mellitus, yes ${ }^{\mathrm{a}}$ & $14(32.6 \%)$ & $7(21.9 \%)$ & \\
\hline Hypertension, yes ${ }^{\mathrm{a}}$ & $17(39.5 \%)$ & $18(41.9 \%)$ & \\
\hline Anti-inflammatory drugs, yes ${ }^{\mathrm{a}}$ & $5(11.6 \%)$ & $6(18.8 \%)$ & \\
\hline Homocysteine $^{c}$ & $18.4 \pm 6.3^{\mathrm{d}}$ & $13.0 \pm 3.8$ & $4-12.3 \mu \mathrm{mol} / \mathrm{L}$ \\
\hline Vitamin $\mathrm{B} 12^{\mathrm{C}}$ & $310.1 \pm 120.2^{\mathrm{e}}$ & $400.2 \pm 238.0$ & $157-1059 \mathrm{pg} / \mathrm{mL}$ \\
\hline Total cholesterol ${ }^{\mathrm{c}}$ & $210.5 \pm 30.1^{\mathrm{f}}$ & $205 \pm 40.5$ & $150-200 \mathrm{mg} / \mathrm{dL}$ \\
\hline $\mathrm{LDL}^{\mathrm{c}}$ & $133.5 \pm 32.5^{\mathrm{f}}$ & $130.4 \pm 20.8$ & $100-129 \mathrm{mg} / \mathrm{dL}$ \\
\hline $\mathrm{HDL}^{\mathrm{c}}$ & $57.7 \pm 18.4^{\mathrm{f}}$ & $55.3 \pm 15.5$ & $>45 \mathrm{mg} / \mathrm{dL}$ \\
\hline Triglycerides $^{c}$ & $113.0 \pm 60.0^{\mathrm{f}}$ & $125.4 \pm 65.3$ & $60-150 \mathrm{mg} / \mathrm{dL}$ \\
\hline
\end{tabular}

Abbreviations. AD: Alzheimer's disease; SD: standard deviation.

${ }^{a}$ Number of patients, with percentages in parentheses.

${ }^{\mathrm{b}}$ Family history was considered $(+)$ if there was more than one case of Alzheimer's disease in the same family and $(-)$ if the case was sporadic.

${ }^{c}$ Student's $t$-test. Values are mean \pm SD.

d $P<0.0001$, very highly significant difference.

${ }^{\mathrm{e}} P=0.0005$, highly significant difference.

${ }^{\mathrm{f}} P>0.05$, no significant difference.

TABLE 4: Distribution of MTHFR 677C $>$ T genotypes and their allelic frequencies in Alzheimer's cases and controls from different ethnic populations.

\begin{tabular}{|c|c|c|c|c|c|}
\hline \multirow{2}{*}{$\begin{array}{l}\text { Country (population) }{ }^{\mathrm{a}} \\
\text { [Reference] }^{\text {Reforen }}\end{array}$} & \multirow{2}{*}{ No. of cases (no. of controls) } & \multicolumn{3}{|c|}{ Distribution of rs1801133 SNP genotypes } & \multirow{2}{*}{ Frequency of T allele } \\
\hline & & $\mathrm{C} / \mathrm{C}$ & $\mathrm{C} / \mathrm{T}$ & $\mathrm{T} / \mathrm{T}$ & \\
\hline Poland (Caucasian) [20] & $99(100)$ & $53.5(55.0)$ & $38.4(38.0)$ & $8.1(7.0)$ & $27.3^{c}(26.0)$ \\
\hline Iran (others) [21] & $117(125)$ & $48.7(67.2)$ & $37.6(26.4)$ & $13.7(6.4)$ & $32.5^{\mathrm{d}}(19.6)$ \\
\hline N. Ireland (Caucasian) [22] & $83(71)$ & $71.1(70.4)$ & $24.1(26.8)$ & $4.8(2.8)$ & $33.7^{\mathrm{d}}(16.2)$ \\
\hline China (East Asia) [23] & $104(100)$ & $48.1(60.8)$ & $36.5(36.2)$ & $15.4(3.0)$ & $33.7^{\mathrm{d}}(21.2)$ \\
\hline Brazil (others) [24] & $30(29)$ & $36.7(51.7)$ & $56.7(37.9)$ & $6.6(10.4)$ & $35.0^{\mathrm{d}}(29.7)$ \\
\hline Egypt (current study) & $43(32)$ & $41.9(62.5)$ & $39.5(31.2)$ & $18.6(6.3)$ & $38.4^{c}(21.9)$ \\
\hline China (East Asia) [25] & $105(102)$ & $37.1(33.3)$ & $42.9(48.0)$ & $20.0(18.7)$ & $41.4^{\mathrm{c}}(42.6)$ \\
\hline United States (Caucasian) [26] & $124(97)$ & $33.0(38.0)$ & $50.5(59.9)$ & $16.5(11.1)$ & $41.8^{\mathrm{c}}(36.5)$ \\
\hline Japan (East Asian) [27] & $194(379)$ & $33.0(38.0)$ & $50.5(50.9)$ & $16.5(11.1)$ & $41.8^{\mathrm{c}}(36.5)$ \\
\hline Israel (others) [28] & $49(40)$ & $24.5(37.5)$ & $63.3(40.0)$ & $12.2(22.2)$ & $45.7^{\mathcal{C}}(42.5)$ \\
\hline Italy (Caucasian) [29] & $231(137)$ & $27.7(28.5)$ & $52.0(47.4)$ & $20.3(24.1)$ & $46.3^{\mathrm{c}}(47.8)$ \\
\hline China (East Asian) [30] & $386(375)$ & $46.4(24.0)$ & $32.4(45.9)$ & $44.4(30.1)$ & $55.6^{\mathrm{c}}(53.1)$ \\
\hline Sweden (Caucasian) [31] & $204(172)$ & $48.0(48.3)$ & $44.1(39.5)$ & $7.9(12.2)$ & $59.8(32.0)$ \\
\hline Korea (East Asian) [32] & $86(625)$ & $12.8(19.5)$ & $50.0(53.1)$ & $37.2(27.4)$ & $62.2^{\mathrm{c}}(53.9)$ \\
\hline
\end{tabular}

Abbreviations. AD: Alzheimer's disease, SNP: single nucleotide polymorphism.

${ }^{a}$ Populations are arranged in ascending order of the frequency of the $\mathrm{T}$ alleles in Alzheimer's cases.

${ }^{\mathrm{b}}$ Genotype distributions of AD cases, with distributions of controls in parentheses.

${ }^{c}$ The distribution of the MTHFR 677T allele does not differ between Alzheimer's cases and controls $(P>0.05)$.

${ }^{\mathrm{d}}$ The distribution of the MTHFR $677 \mathrm{~T}$ allele is significantly different between Alzheimer's cases and controls $(P<0.05)$

Asians but not in Caucasians [34]. This supports the results of our study, which found no significant association between the $677 \mathrm{C}>\mathrm{T}$ polymorphism and $\mathrm{AD}$. Although a positive association has been found between MTHFR genotypes and $\mathrm{AD}$ in East Asians [30,34], the samples that were tested were smaller for East Asians than for Caucasians. Moreover, the control groups in some studies were non-demented individuals or hospital-based controls, which could have greatly affected the results.

Sporadic forms of $\mathrm{AD}$ generally affect patients later in life, with onset usually occurring between the ages of 60 and 70 . Although sporadic cases made up the majority of 
$\mathrm{AD}$ cases in our study, $4.7 \%$ of the cases were genetically linked familial forms of AD. Of the sporadic cases, most were late-onset cases with a complex etiology due to interactions between environmental conditions and genetic features of the individual. A major susceptibility gene, $A p o E$, is commonly associated with sporadic late-onset $\mathrm{AD}$ [35]. Our results with the MTHFR gene are in agreement with other studies suggesting that polymorphisms in other genes, such as genes for the amyloid precursor protein (APP, MIM 104760), presenilin 1 (PSEN1, MIM 104311), and presenilin 2 (PSEN2, MIM 600759), account for less than $5 \%$ of $\mathrm{AD}$ cases $[35,36]$.

Several case-control studies have found AD patients to be deficient in certain micronutrients such as folate and vitamin B12 but to have elevated levels of the sulfur-based amino acid homocysteine. The essential inquiry remains whether the observed high homocysteine levels are a cause or a consequence of AD. Normal homocysteine levels range from 4 to $12.3 \mu \mathrm{mol} / \mathrm{L}$, and these levels increase with age. High levels of homocysteine are common in the elderly demented population, and some studies report that this is probably secondary factors in most cases [15].

Our study clearly shows that the level of homocysteine in plasma was significantly higher $(P<0.0001)$ in $\mathrm{AD}$ cases than in controls. As expected, this suggests that hyperhomocysteinaemia is an independent risk factor for the development of $\mathrm{AD}$, which is consistent with most studies $[16,18]$. Moreover, we found that our AD cases had significantly lower levels of vitamin B12 $(P=0.0005)$, as similarly shown by Wang et al. [23]. Plasma homocysteine has been reported as a sensitive marker for deficiencies of both vitamin B12 and folates in tissues of the psychogeriatric population.

Moore et al. [9] showed that low serum levels of vitamin B12 are associated with neurodegenerative disease and cognitive impairment and that vitamin B12 therapy does not improve cognition in patients without preexisting deficiency. This result was not confirmed by Coppedè et al. [37], who reported that differences in serum vitamin B12 levels between AD cases $(n=378)$ and non-demented controls $(n=308)$ did not reach statistical significance.

Several studies have dealt with the effect of cathepsin B, a candidate protease involved in the conversion of $\beta$-amyloid precursor protein into the amyloid plaques, on $\mathrm{AD}$. Sundelöf et al. [38] have reported that cathepsin B in plasma was higher in persons with $\mathrm{AD}$ compared to healthy controls $(P=0.05)$. Consequently, these outcomes have demonstrated pharmacogenetic differences in the effects of inhibitors of cathepsin B to improve memory deficits. Therefore, inhibitors of cathepsin B or even deletion of the cathepsin B gene may be an effective drug target for improving memory deficits in most AD patients [39].

Our results identified a trend in which the prevalence of $\mathrm{AD}$ decreased with more years of education. Among the patients with $\mathrm{AD}, 19 \%$ were illiterate, $72 \%$ had $<8$ years of education, and $9 \%$ had a higher level of education. These results agree with those of a recent Egyptian study [6] reporting a significantly higher prevalence of dementia among illiterate study participants $(6.4 \% ; P<0.0001)$ than among educated ones $(0.6 \%)$. However, in addition to education, other lifestyle patterns such as diet, exercise, social interaction, worship attendance, alcohol consumption, and smoking may protect against clinical manifestation of $\mathrm{AD}$.

The estimated sample size needed to reveal differences in allele frequencies between the $\mathrm{AD}$ and control groups (aiming at a power of $80 \%$ ) was 128 in each group (a total of 256 participants). Based on differences in the allele frequencies of the $677 \mathrm{C}>\mathrm{T}$ polymorphism between our 43 $\mathrm{AD}$ cases and 32 controls, our post hoc statistical analysis revealed a power of $33 \%$. However, recruiting more elderly participants within a reasonable time frame from a single center would have been difficult. Hence, replication of our results through larger, multicenter genetic association studies will be important.

The present study had several additional limitations. First, because certain regions of the world are only beginning to recognize the magnitude of the $\mathrm{AD}$ burden, sufficient data may be lacking for a realistic understanding of the genetic drift of the mutant 677T allele in patients with AD. Second, a lack of healthcare resources and financial support in Egypt, as in most developing countries, affects the ability to study all possible clinical factors that could have affected the severity of the disease. Also, the patients with $\mathrm{AD}$ may have had other clinical risk factors that are associated with mutations or polymorphisms in the MTHFR gene or with $\mathrm{AD}$, such as hypertension, coronary artery disease, stroke, and cancer. Third, we initially wanted to test folate levels and their association with $\mathrm{AD}$, but we could not track the majority of $\mathrm{AD}$ patients for this assay and so excluded it from our study.

\section{Conclusions}

This is the first study, to our knowledge, to report some association between the MTHFR $677 \mathrm{C}>\mathrm{T}$ polymorphism and $\mathrm{AD}$ in the Egyptian population. We found that the MTHFR $\mathrm{T} / \mathrm{T}$ genotype and the $\mathrm{T}$ allele were significantly associated with severity of $\mathrm{AD}$ and that their frequencies in the Egyptian population are midway between those found in different ethnic populations. However, the high prevalence of benign polymorphisms in the general population and our limited sample size (43 cases and 32 controls) may help to explain why no statistically significant associations were found. In addition, the concentration of plasma homocysteine was increased in $\mathrm{AD}$ cases, and this may be associated with the MTHFR 677T/T genotype.

The literature on the relationship between the MTHFR $677 \mathrm{C}>\mathrm{T}$ polymorphism and $\mathrm{AD}$ in the Middle East is limited. Larger trials with larger patient populations are needed to reach definite conclusions as to whether this polymorphism is a noteworthy risk factor for $\mathrm{AD}$. It is unlikely that the MTHFR $677 \mathrm{C}>\mathrm{T}$ polymorphism is sufficient to cause a complex array of symptoms. The identification of new susceptibility genes has opened new avenues for exploring the underlying disease mechanisms for $\mathrm{AD}$.

\section{Conflict of Interests}

The authors report no conflict of interests. 


\section{Acknowledgments}

The authors wish to thank the staff of Ain Shams University Hospitals, Cairo,Egypt, for providing blood samples from the patients with $\mathrm{AD}$. They also thank all participants' families for their willingness to collaborate with them in this research.

\section{References}

[1] B. Biscaro, O. Lindvall, G. Tesco, C. T. Ekdahl, and R. M. Nitsch, "Inhibition of microglial activation protects hippocampal neurogenesis and improves cognitive deficits in a transgenic mouse model for Alzheimer's disease," Neurodegenerative Diseases, vol. 9, pp. 187-198, 2012.

[2] C. P. Ferri, M. Prince, C. Brayne et al., "Global prevalence of dementia: a Delphi consensus study," The Lancet, vol. 366, no. 9503, pp. 2112-2117, 2005.

[3] J. J. L. Rodriguez, C. P. Ferri, D. Acosta et al., "Prevalence of dementia in Latin America, India, and China: a populationbased cross-sectional survey," The Lancet, vol. 372, no. 9637, pp. 464-474, 2008.

[4] G. K. York III and D. A. Steinberg, "Neurology in ancient Egypt," in Handbook of Clinical Neurology, vol. 95, chapter 3, pp. 29-36, Elsevier, 2009.

[5] E. H. Jiffri and N. A. Elhawary, "The impact of common tumor necrosis factor haplotypes on the development of asthma in children: an egyptian model," Genetic Testing and Molecular Biomarkers, vol. 15, no. 5, pp. 293-299, 2011.

[6] H. N. El Tallawy, W. M. A. Farghly, G. A. Shehata et al., "Prevalence of dementia in Al Kharga District, New Valley Governorate, Egypt," Neuroepidemiology, vol. 38, no. 3, pp. 130137, 2012.

[7] M. S. Saarela, T. Lehtimäki, J. O. Rinne et al., "No association between the brain-derived neurotrophic factor 196G $>$ A or $270 \mathrm{C}>\mathrm{T}$ polymorphisms and Alzheimer's or Parkinson's disease," Folia Neuropathologica, vol. 44, no. 1, pp. 12-16, 2006.

[8] S. J. Duthie, L. J. Whalley, A. R. Collins, S. Leaper, K. Berger, and I. J. Deary, "Homocysteine, B vitamin status, and cognitive function in the elderly," The American Journal of Clinical Nutrition, vol. 75, pp. 908-913, 2002.

[9] E. Moore, A. Mander, D. Ames, R. Carne, K. Sanders, and D. Watters, "Cognitive impairment and vitamin B12: a review," International Psychogeriatrics, vol. 24, no. 4, pp. 541-556, 2012.

[10] E. A. Varga, A. C. Sturm, C. P. Misita, and S. Moll, "Homocysteine and MTHFR mutations: relation to thrombosis and coronary artery disease," Circulation, vol. 111, no. 19, pp. e289e293, 2005.

[11] I. M. van Beynum, M. den Heijer, H. J. Blom, and L. Kapusta, "The MTHFR 677C $\rightarrow$ T polymorphism and the risk of congenital heart defects: a literature review and meta-analysis," QJM, vol. 100, no. 12, pp. 743-753, 2007.

[12] J. Chen, M. D. Gammon, W. Chan et al., "One-carbon metabolism, MTHFR polymorphisms, and risk of breast cancer," Cancer Research, vol. 65, no. 4, pp. 1606-1614, 2005.

[13] I. Bjelland, G. S. Tell, S. E. Vollset, H. Refsum, and P. M. Ueland, "Folate, vitamin B12, homocysteine, and the MTHFR 677C $\rightarrow$ $\mathrm{T}$ polymorphism in anxiety and depression. The Hordaland Homocysteine Study," Archives of General Psychiatry, vol. 60, no. 6, pp. 618-626, 2003.
[14] P. Frosst, H. J. Blom, R. Milos et al., "A candidate genetic risk factor for vascular disease: a common mutation in methylenetetrahydrofolate reductase," Nature Genetics, vol. 10, no. 1, pp. 111113, 1995.

[15] P. Ventura, R. Panini, C. Verlato, G. Scarpetta, and G. Salvioli, "Hyperhomocysteinemia and related factors in 600 hospitalized elderly subjects," Metabolism, vol. 50, no. 12, pp. 1466-1471, 2001.

[16] S. Seshadri, A. Beiser, J. Selhub et al., "Plasma homocysteine as a risk factor for dementia and Alzheimer's disease," The New England Journal of Medicine, vol. 346, no. 7, pp. 476-483, 2002.

[17] L. Flicker, R. N. Martins, J. Thomas et al., "B-vitamins reduce plasma levels of beta amyloid," Neurobiology of Aging, vol. 29, no. 2, pp. 303-305, 2008.

[18] M. C. Morris, D. A. Evans, J. A. Schneider, C. C. Tangney, J. L. Bienias, and N. T. Aggarwal, "Dietary folate and vitamins B12 and B-6 not associated with incident Alzheimer's disease," Journal of Alzheimer's Disease, vol. 9, no. 4, pp. 435-443, 2006.

[19] A. R. Koudinov and N. V. Koudinova, "Cholesterol homeostasis failure as a unifying cause of synaptic degeneration," Journal of the Neurological Sciences, vol. 229-230, pp. 233-240, 2005.

[20] D. Religa, M. Styczynska, B. Peplonska et al., "Homocysteine, apolipoproteine $\mathrm{E}$ and methylenetetrahydrofolate reductase in Alzheimer's disease and mild cognitive impairment," Dementia and Geriatric Cognitive Disorders, vol. 16, no. 2, pp. 64-70, 2003.

[21] M. R. Keikhaee, S. B. Hashemi, H. Najmabadi, and M. Noroozian, "C677T methylentetrahydrofulate reductase and angiotensin converting enzyme gene polymorphisms in patients with Alzheimer's disease in Iranian population," Neurochemical Research, vol. 31, no. 8, pp. 1079-1083, 2006.

[22] S. P. McIlroy, K. B. Dynan, J. T. Lawson, C. C. Patterson, and A. P. Passmore, "Moderately elevated plasma homocysteine, methylenetetrahydrofolate reductase genotype, and risk for stroke, vascular dementia, and Alzheimer disease in Northern Ireland," Stroke, vol. 33, no. 10, pp. 2351-2356, 2002.

[23] B. Wang, F. Jin, R. Kan et al., "Association of MTHFR gene polymorphism C677T with susceptibility to late-onset Alzheimer's disease," Journal of Molecular Neuroscience, vol. 27, no. 1, pp. 2328, 2005.

[24] L. L. Fernandez and R. M. Scheibe, "Is MTHFR polymorphism a risk factor for Alzheimer's disease like APOE?" Arquivos de Neuro-Psiquiatria, vol. 63, no. 1, pp. 1-6, 2005.

[25] Y. D. Zhang, X. Y. Ke, W. Shen, and Y. Liu, "Relationship of homocysteine and gene polymorphisms of its related metabolic enzymes with Alzheimer's disease," Chinese Medical Sciences Journal, vol. 20, no. 4, pp. 247-251, 2005.

[26] D. Seripa, G. Dal Forno, M. G. Matera et al., "Methylenetetrahydrofolate reductase and angiotensin converting enzyme gene polymorphisms in two genetically and diagnostically distinct cohort of Alzheimer patients," Neurobiology of Aging, vol. 24, no. 7, pp. 933-939, 2003.

[27] T. Kida, K. Kamino, M. Yamamoto et al., "C677T polymorphism of methylenetetrahydrofolate reductase gene affects plasma homocysteine level and is a genetic factor of late-onset Alzheimer's disease," Psychogeriatrics, vol. 4, no. 1, pp. 4-10, 2004.

[28] J. Chapman, N. Wang, T. A. Treves, A. D. Korczyn, and N. M. Bornstein, "ACE, MTHFR, factor V Leiden, and APOE polymorphisms in patients with vascular and Alzheimer's dementia," Stroke, vol. 29, no. 7, pp. 1401-1404, 1998.

[29] T. Brunelli, S. Bagnoli, B. Giusti et al., "The C677T methylenetetrahydrofolate reductase mutation is not associated with 
Alzheimer's disease," Neuroscience Letters, vol. 315, no. 1-2, pp. 103-105, 2001.

[30] X.-H. Bi, H.-L. Zhao, Z.-X. Zhang, and J.-W. Zhang, "Association of RFC1 A80G and MTHFR C677T polymorphisms with Alzheimer's disease," Neurobiology of Aging, vol. 30, no. 10, pp. 1601-1607, 2009.

[31] J. A. Prince, L. Feuk, S. L. Sawyer et al., "Lack of replication of association findings in complex disease: an analysis of 15 polymorphisms in prior candidate genes for sporadic Alzheimer's disease," European Journal of Human Genetics, vol. 9, no. 6, pp. 437-444, 2001.

[32] J.-M. Kim, R. Stewart, S.-W. Kim et al., "Methylenetetrahydrofolate reductase gene and risk of Alzheimer's disease in Koreans," International Journal of Geriatric Psychiatry, vol. 23, no. 5, pp. 454-459, 2008.

[33] R. M. Shawky, N. S. Sayed, and N. A. Elhawary, "Mutations in transglutaminase 1 gene in autosomal recessive congenital ichthyosis in Egyptian families," Disease Markers, vol. 20, no. 6, pp. 325-332, 2004.

[34] M.-Y. Zhang, L. Miao, Y.-S. Li, and G.-Y. Hu, "Meta-analysis of the methylenetetrahydrofolate reductase C677T polymorphism and susceptibility to Alzheimer's disease," Neuroscience Research, vol. 68, no. 2, pp. 142-150, 2010.

[35] A. Rocchi, S. Pellegrini, G. Siciliano, and L. Murri, "Causative and susceptibility genes for Alzheimer's disease: a review," Brain Research Bulletin, vol. 61, no. 1, pp. 1-24, 2003.

[36] R. J. Guerreiro, E. Lohmann, E. Kinsella et al., "Exome sequencing reveals an unexpected genetic cause of disease: NOTCH3 mutation in a Turkish family with Alzheimer's disease," Neurobiology of Aging, vol. 33, no. 5, pp. e17-e23, 2012.

[37] F. Coppedè, P. Tannorella, I. Pezzini et al., "Folate, homocysteine, vitamin $\mathrm{B} 12$, and polymorphisms of genes participating in one-carbon metabolism in late-onset Alzheimer's disease patients and healthy controls," Antioxidants \& Redox Signaling, vol. 17, no. 2, pp. 195-204, 2012.

[38] J. Sundelöf, J. Sundström, O. Hansson et al., "Higher cathepsin B levels in plasma in Alzheimer's disease compared to healthy controls," Journal of Alzheimer's Disease, vol. 22, no. 4, pp. 12231230, 2010.

[39] M. S. Kindy, J. Yu, H. Zhu, S. S. El-Amouri, V. Hook, and G. R. Hook, "Deletion of the cathepsin B gene improves memory deficits in a transgenic alzheimer's disease mouse model expressing $\mathrm{A} \beta \mathrm{PP}$ containing the wild-type $\beta$-secretase site sequence," Journal of Alzheimer's Disease, vol. 29, no. 4, pp. 827-840, 2012. 